\title{
The Effect of Relative Humidity and Roughness on the Friction Coefficient under Horizontal Vibration
}

\author{
Mohammad Asaduzzaman Chowdhury ${ }^{*}, 1$ and Maksud Helali ${ }^{2}$ \\ ${ }^{1}$ Department of Mechanical Engineering, Dhaka University of Engineering and Technology, Gazipur, Gazipur-1700, \\ Bangladesh \\ ${ }^{2}$ Department of Mechanical Engineering, Bangladesh University of Engineering and Technology, Dhaka-1000, \\ Bangladesh
}

\begin{abstract}
The present paper investigates experimentally the effect of relative humidity and roughness on friction property of mild steel under horizontal vibration. To do so, a pin-on-disc apparatus having facility of vibrating the test samples at different direction is designed and fabricated. The direction of vibration is horizontal. Horizontal vibration is created along (longitudinal direction) and perpendicular (transverse direction) to the sliding direction. The experimental setup has the facility to vary the amplitudes and frequencies of vibration while velocity of vibration is kept constant. During the experiment, relative humidity, roughness, frequency, amplitude and direction of vibration are varied. The observed ranges of relative humidity and surface roughness were $40 \%-80 \%$ and $0.125-2.5 \mu m$ (RMS) respectively. Results show that friction co-efficient decreases with the increase of relative humidity for horizontal vibration. Friction coefficient is very high at very low roughness and it tends to be high at very high roughness for horizontal direction. It is also observed that the variation of friction co-efficient has a particular relationship with the relative humidity and roughness under horizontal vibration.
\end{abstract}

Keywords: Friction coefficient, horizontal vibration, relative humidity, roughness.

\section{INTRODUCTION}

Study of mechanics of friction and the relationship between friction and wear dates back to the sixteenth century, almost immediately after the invention of Newton's law of motion. The basic laws of friction are generally obeyed with a little variation which is within a few percent in many cases. It should be emphasized that coefficient of friction $(\mu)$ is strictly constant only for a given pair of sliding materials under a given set of operating conditions (temperature, humidity, normal pressure and sliding velocity). Several authors [1-4] observed that the variation of friction force depends on roughness of the rubbing surfaces, relative motion, type of material, temperature, normal force, stick slip, relative humidity, lubrication and vibration. Due to this frictional variation, they observed that no clear correlation has yet, been established. They also found that there are various hypothesis but these differ considerably. Therefore, they suggested that more research is needed for the implication of past and future results to be clearly understood.

Researchers [5-16] have concluded that mean friction force increases as well as decreases depending on the vibration parameters. The measurements of static and dynamic frictional forces by the researchers under the influence of external vibrations indicate three different or opposite trends and these trends are:

*Address correspondence to this author at the Department of Mechanical Engineering, Dhaka University of Engineering and Technology, Gazipur, Gazipur-1700, Bangladesh; Tel: 880-2-9204734-43, Ext. 435; Fax: 880-29204701-02; E-mail: asadzmn2003@yahoo.com
1) The frictional force is increased by vibrational assistance.

2) The frictional force is not changed or slightly changed by vibrational assistance.

3) The frictional force is reduced by vibrational assistance.

These trends were observed when the parameters involved in the process i.e. normal force, amplitude, frequency, material and surface were changed. Thus the frictional force can be increased or decreased as a result of an adequate choice of parameters. The investigation by different authors showed that either an increase or a decrease in the frictional forces can be obtained when one of the parameters like, surface pressure, frequency or amplitude is changed. The above results indicate the domain of specific behaviors i.e. certain mechanisms cause a friction to increase while others to decrease. In some cases, the mechanisms are balanced and will not affect the friction. The frictional force can be weakened mainly through a separation of the surfaces or strengthened by welding phenomena in the contact surfaces.

A decrease in frictional force can be obtained through (a) resonance between the natural frequency of the contacting asperities and that of the external vibration, (b) reversal of the friction vector, (c) superposition between static and dynamic load, which means that a lower tangential force is needed to initiate the sliding of materials in the friction surface or (d) local transformation of vibration energy into heat energy in the friction surface, so that the yield point of the material is lowered. An increase in the frictional force can be obtained through (a) viscous damping of the friction 
surface, (b) increased adhesion or microwelding (pick-ups) between the materials or (c) deformation and material hardening of the material (the microhardness has been affected during the investigation).

The complexity of friction makes it difficult to identify the basic mechanisms responsible for these results.

Chowdhury and Helali found that friction coefficient is a function of amplitude and roughness under vertical vibration [17]. They observed the effect of frequency and amplitude of vertical vibration on friction coefficient at a particular roughness and relative humidity [18]. They also showed that increase or decrease of friction coefficient depends on direction of vibration [19]. On the other hand friction coefficient increases with the decrease of relative humidity [2022]. Experiments were conducted by Chowdhury and Helali [23-24] to determine the simultaneous effect of frequency of vertical vibration and humidity on friction and wear and found that the friction coefficient and wear rate decreases with the increase of frequency of vertical vibration and relative humidity. They also found percentage reduction of friction coefficient is almost constant for a particular frequency of vertical vibration for different relative humidity. That is, the previous investigations have been carried out for mild steel to observe the effect of roughness on friction coefficient for different amplitudes, frequencies and relative humidity under vertical vibration. However, the effects humidity and roughness on friction coefficient in conjunction with frequencies and amplitudes of horizontal vibration are yet to be investigated. Therefore, in this study an attempt is made to investigate the effect of humidity and roughness on friction coefficient under horizontal vibration for mild steel. In this study vibration is generated artificially in such a way that direction, amplitude and frequency of vibration can be controlled. Within this research it is sought to better understand the relation between friction and relative humidity and roughness for horizontal vibration and to explore the possibility of adding controlled relative humidity and roughness with horizontal vibration to a mechanical process as a means to improve performance and quality. It is expected that the applications of these results will contribute to the improvement of different concerned mechanical systems.

\section{EXPERIMENTAL SETUP}

Fig. (1) shows a pin-on-disc machine which contains a pin that can slide on a rotating horizontal surface (disc). In this set-up a circular mild steel (carbon 0.19-0.2\%) test sample (disc) is to be fixed on a rotating plate (table) having a long vertical shaft clamped with a screw from the bottom surface of the rotating plate. The shaft passes through two close-fit bush-bearings which are rigidly fixed with twosquare plates such that the shaft can move only axially and any radial movement of the rotating shaft is restrained by the bush. All these two supporting square plates along with a base plate are rigidly fixed with four vertical square bars to provide the rigidity to the main structure of this set-up. The base plate was fixed with rubber block impagnated with steel plate. A compound V-pulley above the top supporting square

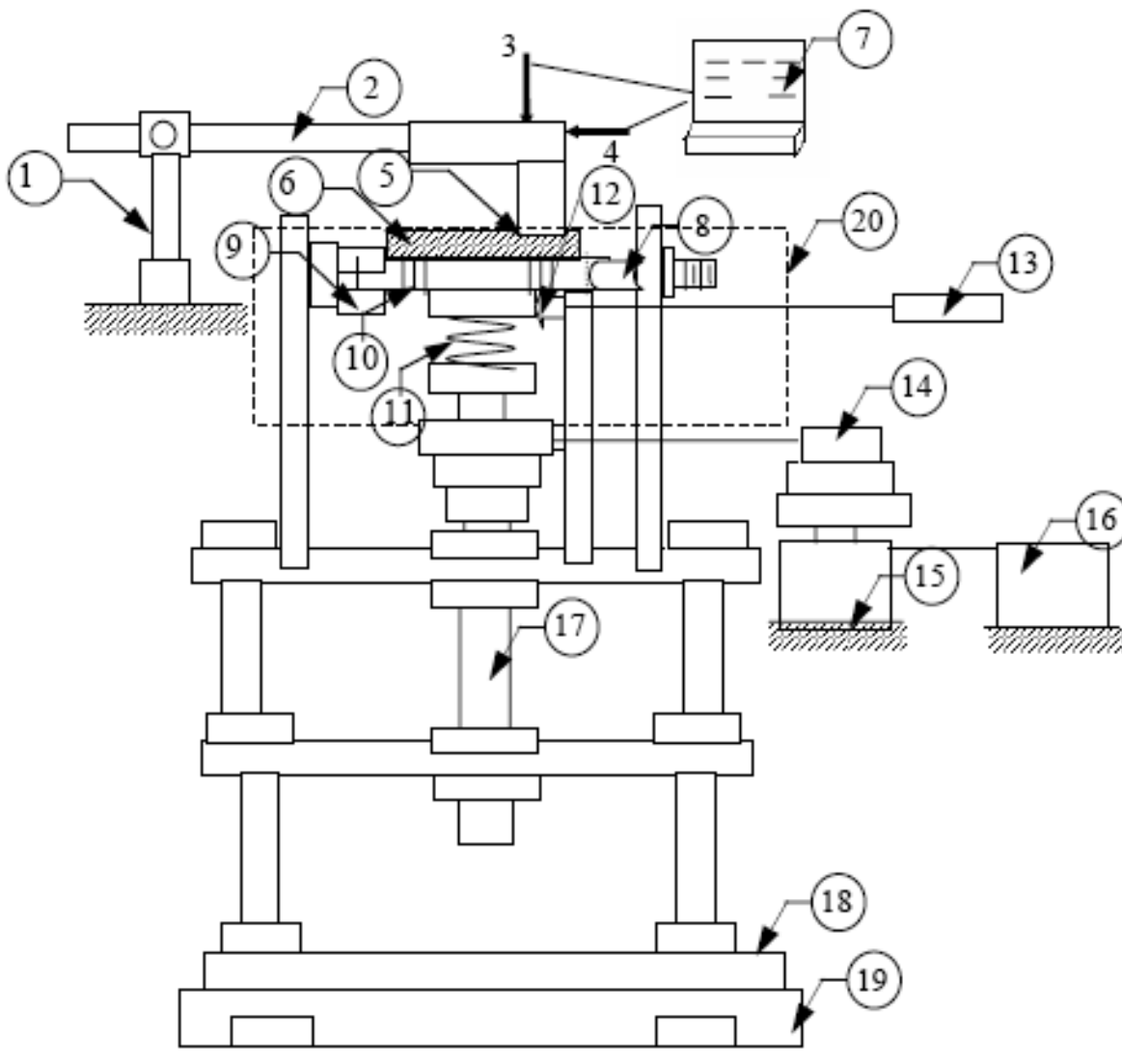

1. Load arm holder

2. Load arm

3. Normal load (dead weight)

4. Horizontal load

5. Pin sample with pin holder

6. Test disc with slotted rotating table

7. Computer

8. Length adjusting barrier

9. U-shaped adjustable guide

10. V-slots

11. Spring

12. Vibration sensing arrangement

13. Vibration meter

14. Belt and pulley

15. Motor

16. Speed control unit

17. Main shaft

18. Base plate

19. Rubber block

20. Horizontal vibration

arrangement

Fig. (1). Block diagram of the experimental set-up (Horizontal Vibration). 
plate was fixed with the shaft to transmit rotation to the shaft from a motor. For generating horizontal vibration, one end of a coil spring is fixed with the rotating shaft and other end of the spring is fixed with the rotating table, holding the test plate. Around the circumference of the rotating table, there are a number of V-slots. An adjusting rigid barrier with spherical tip is fixed (as shown in Fig. 1) with the basic structure of the setup. This tip may penetrate into the V-slots of the rotating table. The depth of this penetration is adjustable. Therefore when the shaft along with the spring and table rotates, the tip of the rigid barrier creates obstruction to the rotation of the slotted table. Due to spring action and rotation, the table will vibrate horizontally. To ensure the horizontality of vibration three U-shaped adjustable guides are placed at $120^{\circ}$ apart. These rigid guides are fixed with the basic structure of the setup. The displacement velocity and acceleration diagrams for horizontal vibration are shown in Fig. (2). The direction of vibration can be either longitudinal or transverse depending on the position of sliding pin on the rotating vibrating table. By varying rotation of the shaft and the number of slots of the rotating table, the frequency of vibration can be varied. By adjusting the depth of penetration of the adjustable barrier, the amplitude of the vibration can be varied. With all these supports some vertical vibration may also arise which will be measured and presented along with the results. As the plate is vibrating and rotating, it was not possible to fix directly the vibration sensing pickup of the vibration meter for measuring vibration. So measure the vibration of the table, a spring loaded pin is kept in contact with the lower
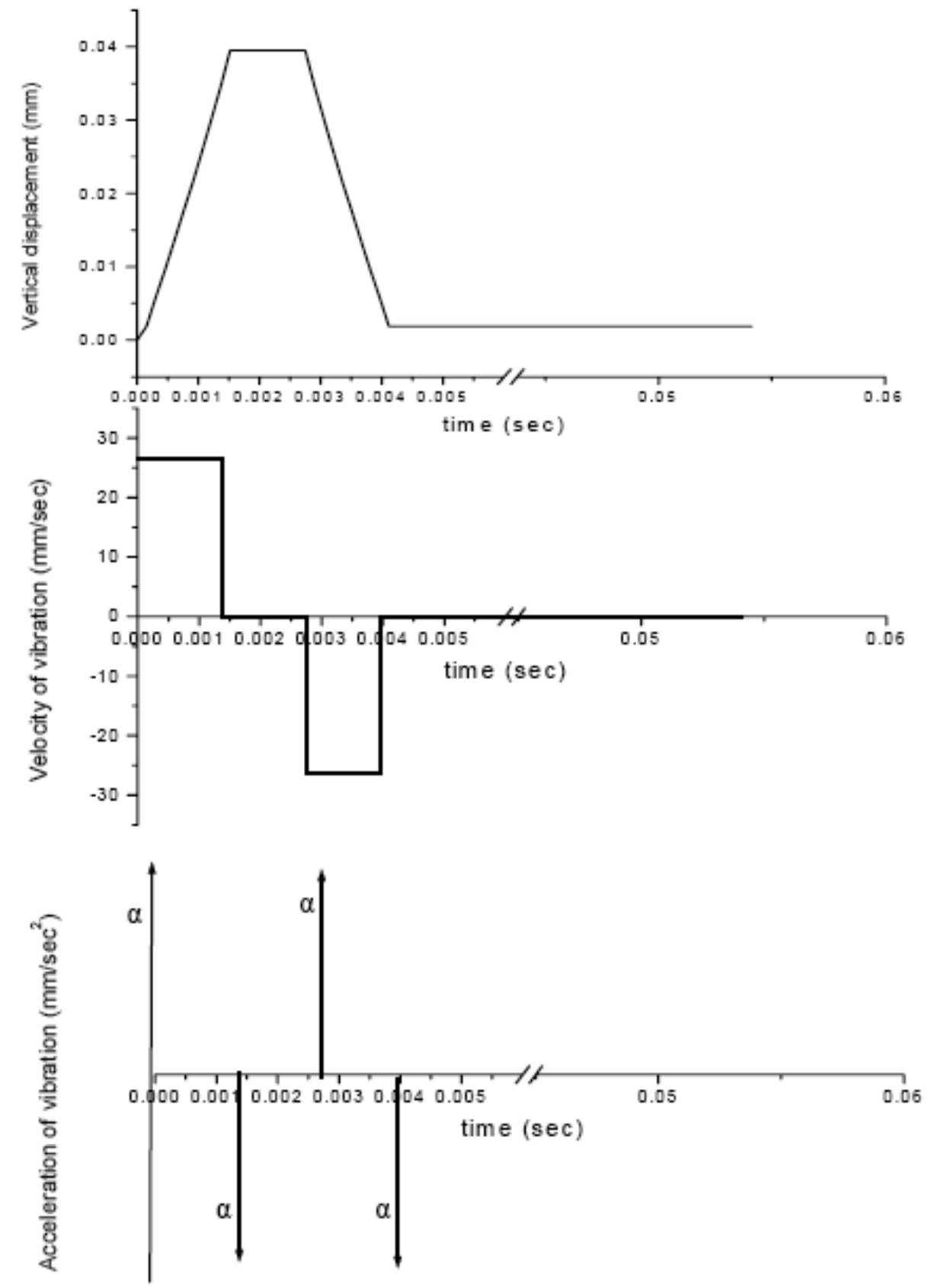

Fig. (2). Displacement, Velocity and Acceleration diagrams for horizontal vibration. 


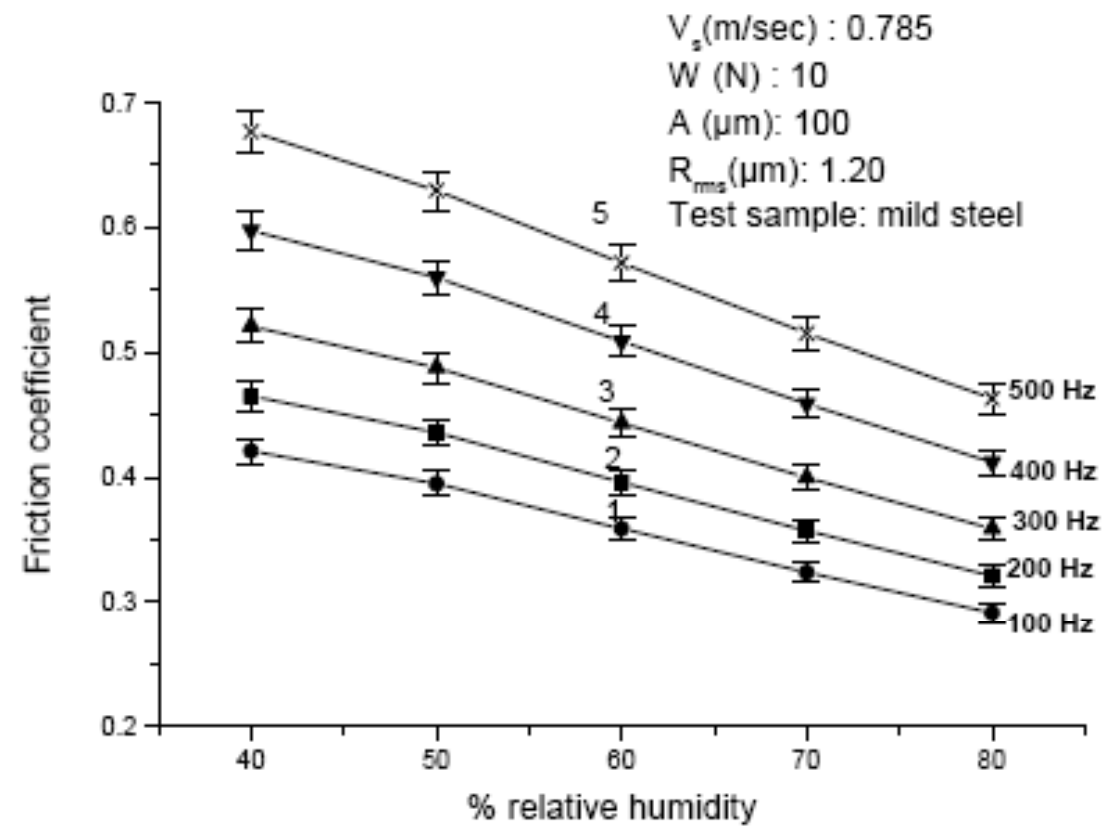

Fig. (3). Friction coefficient vs. relative humidity at different frequency of longitudinal horizontal vibration.

extended portion of the rotating table which will transmit vibration of the plate to the vibration sensing pickup. Sliding velocity can be varied by two ways (i) by changing the rotation of the shaft when frequency also changes and (ii) by changing the radius of the point of contact of the sliding pin when frequency does not change. But change of curvature may affect resisting force measurement. By adjusting the height of this slotted plate the amplitude of the vibration can be varied.

The pin with the holder has rocking mode of vibration due to the cantilever action of the holding arm. Considering the small area of contact of the pin and diameter of the rotating disc the sliding velocity can be taken as linear though the sliding surface is rotating.
To rotate the shaft with the table a one-horsepower motor is mounted vertically on a separate base having rubber damper. This separate base was arranged to reduce the affect of vibration of the motor, which may transmit to the main structure. An electronic speed control unit is used to vary the speed of the motor as required.

A $6 \mathrm{~mm}$ diameter cylindrical pin whose contacting foot is flat made of mild steel, fitted on a holder is subsequently fitted with an arm. The arm is pivoted with a separate base in such a way that the arm with the pin holder can rotate vertically and horizontally about the pivot point with very low friction. This pin can be put to slide at any point of the test sample (disc). Pin holder is designed with the facility of putting dead weight on it so that required normal force will

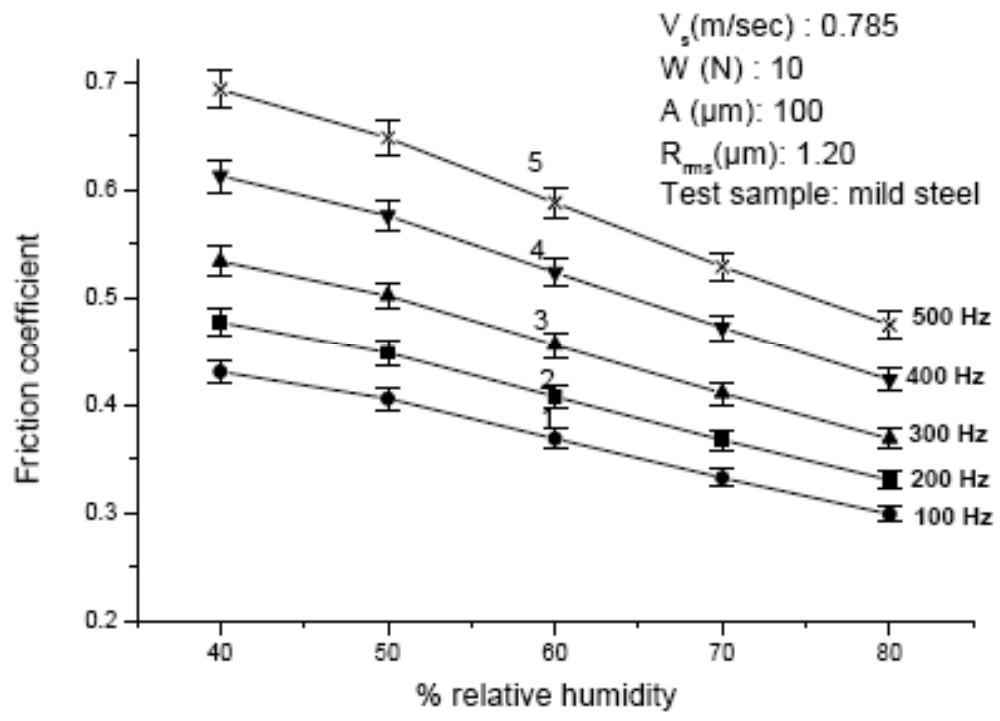

Fig. (4). Friction coefficient vs. relative humidity at different frequency of transverse horizontal vibration. 
act on the test sample through the pin. The shapes of the pin were maintained cylindrical so that due to loss of surface material of the pin the contacting surface will remain almost constant. To measure the frictional force acting on the pin during sliding on the rotating plate, a load cell (TML, Tokyo Sokki Kenkyujo Co. Ltd, CLS-100NA, Serial no. MR2947) is fitted with a side support such that the load cell prevents the movement of the pin holder. During the rotation of the test sample, pin holder creates pressure on the load cell which gives the measure of the frictional force acting on the pin. Another load cell of the same kind was also used to measure the vertical force acting on the pin. The coefficient of friction is measured as the ratio between horizontal and vertical forces. A data acquisition system was used to measure the force continuously when the system is on and these data are sent directly to the computer. Vibration was measured by using a digital vibration meter (METRIX Instrument Co., Miniature Vibration Meter, Model no. 5500B). A load cell along with its digital indicator (TML, Tokyo Sokki Kenkyujo Co. Ltd, Model no. TD-93A) which was calibrated against a standard proving ring was used for measuring loads. Loss of frictional force at pivot point of the pin holding arm was determined and incorporated in the results. The total set-up was placed inside a chamber whose relative humidity can be adjusted by supplying requisite amount of moisture and dehumidifier. A hygrometer (Wet and Dry Bulb Hygrometer, ZEAL, England) was used to measure the relative humidity of the chamber. A tachometer was used to measure the rpm of the rotating shaft. The surface roughnesses of the test sample were also measured by surface roughness tester (Taylor Hobson Precision Roughness Checker). The first natural frequency of the test setup was found to be $820 \mathrm{~Hz}$. During tests each experiment was repeated several times with fresh sample of pin and disc. In the experimental results as shown in Figs. (3-4) and $6-9, \pm 2.5 \%$ error bar has been included.

\section{RESULTS AND DISCUSSIONS}

In this section the results of variation of friction coefficient with the variation of relative humidity and roughness under horizontal vibration has been discussed.

Figs. (3-4) show the variation of friction co-efficient with relative humidity and frequency of vibration. Curves are drawn for different relative humidity with frequency of vibration 100, 200, 300, 400 and $500 \mathrm{~Hz}$.

Curve 1 of Figs. (3) and (4) shows the variation of friction coefficient with the change of relative humidity from $40 \%$ to $80 \%$ for frequency of vibration $100 \mathrm{~Hz}$. The values of friction coefficient of this frequency vary from 0.42 to 0.29 and 0.43 to 0.30 for longitudinal and transverse horizontal vibration respectively. Similar trends of reductions are found for $200-500 \mathrm{~Hz}$ frequencies i.e. the values of friction coefficient decreases almost linearly with the increase of relative humidity for horizontal vibration. The decrease of friction coefficient with the increase of relative humidity may be due to the moistening affect of the test disc surface that may have some lubricating effect reducing its value. Therefore, it may be concluded that friction coefficient decreases with the increase of relative humidity. These findings are in agreement with the findings of Yasuo Imada [22] without vibration condition and Chowdhury and Helali [23-24] under vertical vibration for mild steel. The materials Sn [20] and Ceramic [21], also show similar behavior i.e, friction co-efficient decreases with the increase of relative humidity. It is found from the experimental results that there is no effect of frequency of vibration on the percentage reduction of friction coefficient at a particular relative humidity and these percentage reductions of friction coefficient increase with the increase of relative humidity. These results are shown in Fig. (5) for longitudinal horizontal vibration. Similar trends are observed for transverse horizontal vibration. Note that all these

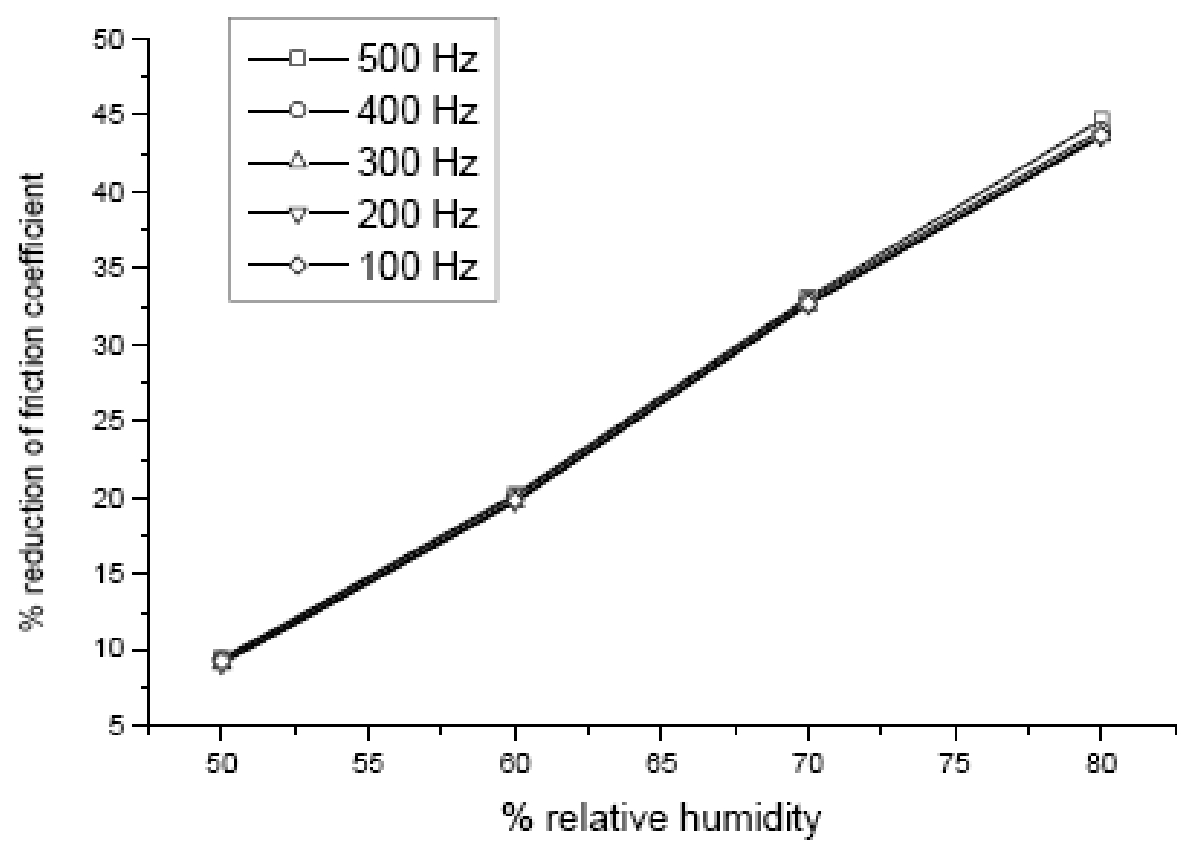

Fig. (5). Percentage reduction of friction coefficient as a function of relative humidity and frequency of longitudinal vibration. 


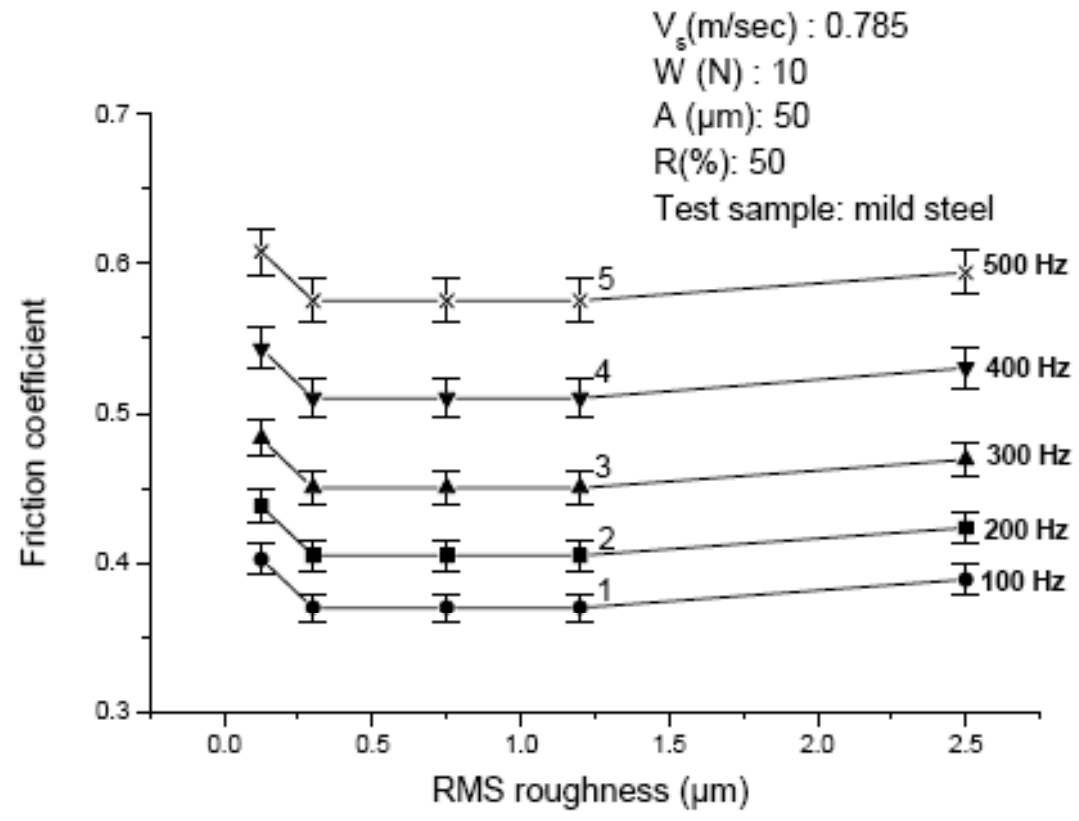

Fig. (6). Friction coefficient vs. RMS roughness at different frequency of longitudinal horizontal vibration.

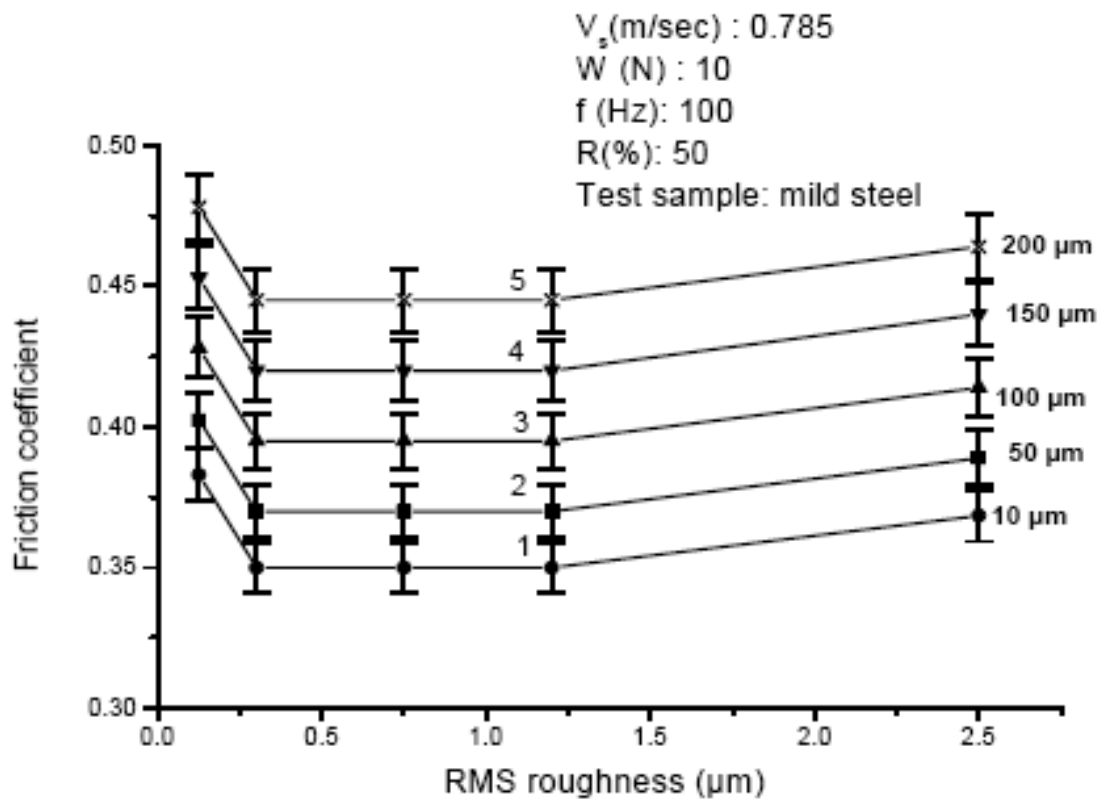

Fig. (7). Friction coefficient $v s$. RMS roughness at different amplitude of longitudinal horizontal vibration.

percentage of variations of friction coefficient are calculated with reference to the values of friction coefficient under $40 \%$ relative humidity.

Figs. (6-9) shows the effect of surface roughness on friction coefficient for mild steel under amplitude of vibration 10 to $200 \mu \mathrm{m}$ and frequency of vibration 100 to $500 \mathrm{~Hz}$ for longitudinal and transverse vibrations. Curves 1 of Figs. (6-8) are drawn for frequency of vibration $100 \mathrm{~Hz}$. It is shown that friction coefficient at very low roughnesses between the ranges of 0.125 to $0.30 \mu \mathrm{m}$ varies from 0.40 to 0.37 and 0.41 to 0.38 for longitudinal and transverse vibrations respectively. For moderate range of roughnesses between 0.30 to $1.20 \mu \mathrm{m}$, the values of friction coefficient are almost constant. The values of friction coefficient are
0.37 for longitudinal vibration and 0.38 for transverse vibration within this range. But roughness in between 1.20 to $2.50 \mu \mathrm{m}$, friction coefficient varies from 0.37 to 0.39 and 0.38 to 0.4 for longitudinal and transverse vibration respectively. Curves 2 to 5 of these figures show the variation of friction coefficient at 200,300, 400 and $500 \mathrm{~Hz}$ frequency of vibration, respectively. These curves show similar trend as that of curve 1. All other parameters such as sliding velocity, normal load, amplitude of vibration and relative humidity were almost identical for these five curves. Similar trends are observed for different amplitude of vibration and these results are presented in Figs. (7) and (9). Friction coefficient is very high at very low roughness because of the growth of real area of contact; it tends to be 


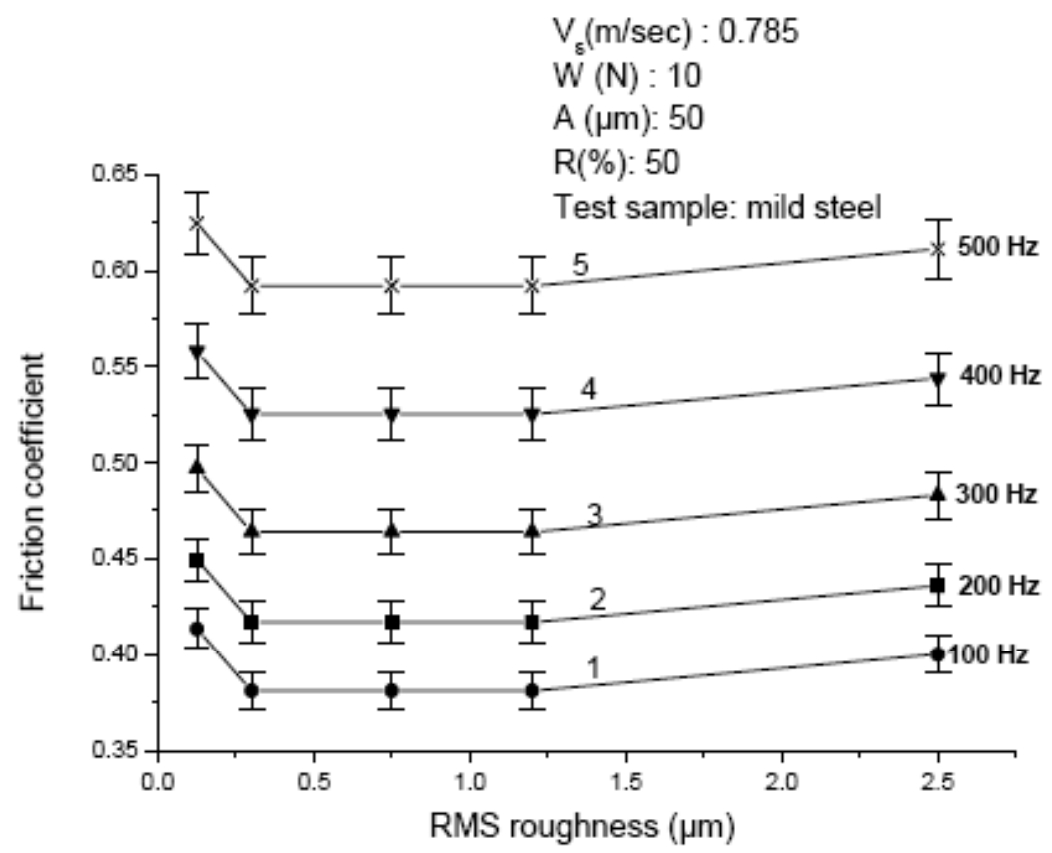

Fig. (8). Friction coefficient vs. RMS roughness at different frequency of transverse horizontal vibration.

high at very high roughness because of mechanical interlocking. Similar tests were done for different frequency of vibration and similar trends of results are observed. It is found from the experimental results that there is no effect of roughness on the percentage reduction of friction coefficient at a particular amplitude and frequency of vibration and these percentage reductions of friction coefficient increase with the increase of frequency and amplitude of vibration for horizontal vibrations. These findings are in agreement the findings of Chowdhury for vertical direction of vibration under different amplitudes [17]. These results are also similar to the results of Bhushan [25] and Rabinowicz [26] for no vibration condition. From the experimental results it can also be concluded that friction coefficient increases with the increase of frequency and amplitude of vibration. The increase of friction coefficient with the increase of amplitude and frequency of vibration for horizontal direction of vibration might be due to the fact that the greater the amplitude of vibration, the higher the distance travel along the sliding direction at which the slider slides. Therefore, the increase of friction coefficient for the increase of amplitude might be due to the increase of length of rubbing with the increase of amplitude of vibration. Addition to these, the increase of friction coefficient might be due to (i) fluctuation of inertia force along the direction of friction force (positive and negative), (ii) more sliding causes more abrasion

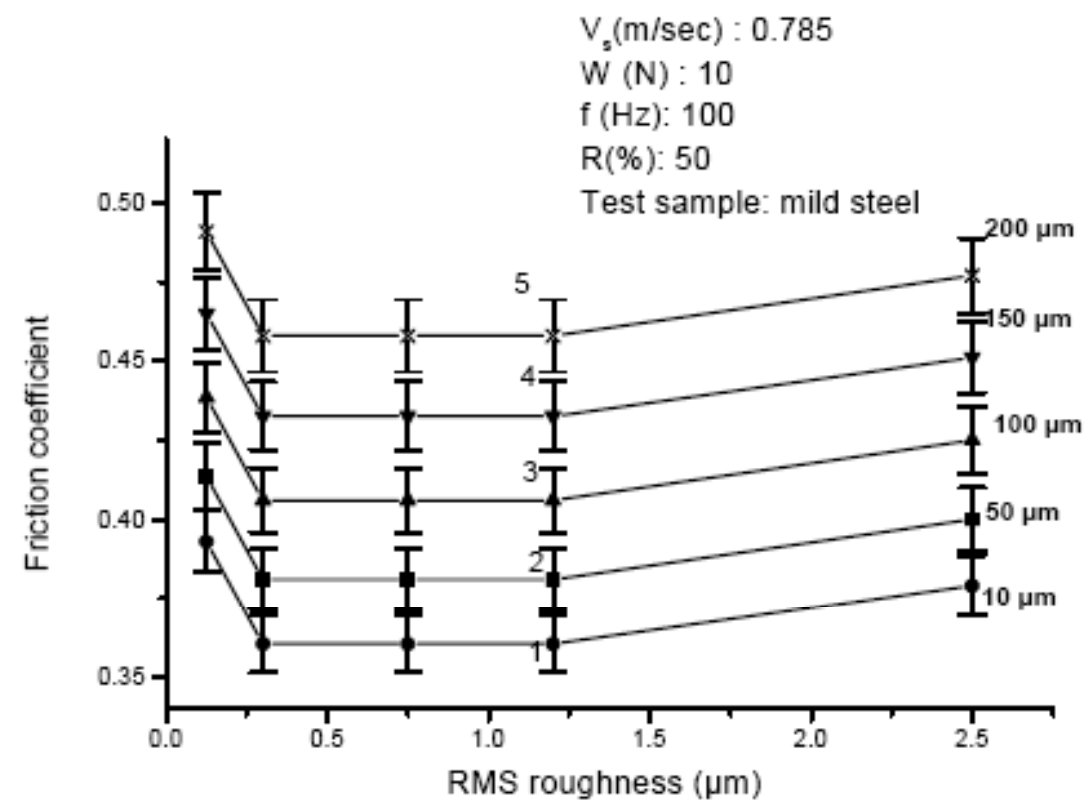

Fig. (9). Friction coefficient vs. RMS roughness at different amplitude of transverse horizontal vibration. 
resistance. Higher abrasion results more shearing due to penetration and ploughing of the asperities between contacting surfaces that might have some effect on the increment of friction force, (iii) micro-welding, reversal of friction vector and mechanical interlocking, (iv) formation and enhance an electrically charge layer at the interface, (v) increase of solubility due to high temperature $[4,16]$.

\section{CONCLUSIONS}

The presence of relative humidity and surface roughness for horizontal direction of vibration indeed affects the friction force considerably. The coefficient of friction is function of relative humidity and frequency of vibration. The values of friction co-efficient decrease with the increase of relative humidity ranging from $40 \%$ to $80 \%$ for frequency of 100 to $500 \mathrm{~Hz}$ of horizontal vibration. There is no effect of frequency of vibration on the percentage reduction of friction coefficient at a particular relative humidity and these percentage reductions of friction coefficient increase with the increase of relative humidity. There is a particular relationship between friction coefficient and surface roughness under transverse and longitudinal horizontal vibration. The variation of friction coefficient with the variation of roughness shows almost similar trends both for different amplitudes and frequencies. The coefficient of friction is high at low roughness, remains constant at moderate range and also high at high roughness under horizontal vibration. Roughness has no effect on the percentage reduction of friction coefficient at a particular amplitude and frequency of horizontal vibration and these percentage reductions of friction coefficient increase with the increase of frequency and amplitude for horizontal vibrations. Results show that coefficient of friction increases with the increase of frequency and amplitude of horizontal vibration for different humidities and roughnesses. As the friction co-efficient decreases with increasing relative humidity and the friction coefficient shows different approaches with low, moderate and high ranges of surface roughness so by maintaining an appropriate level of humidity and roughness for horizontal vibrations friction may be kept to some lower optimum value.

\section{REFERENCES}

[1] J.F. Archard, "Wear Theory and Mechanisms," Wear Control Handbook, M.B. Peterson and W.O. Winer, Eds., ASME, New York, NY, 1980, pp. 35-80.

[2] D. Tabor, "Friction and Wear - Developments Over the Last 50 Years," Keynote Address, Proc. International Conf. Tribology Friction, Lubrication and Wear, 50 Years On, London, Inst. Mech. Eng., 1987, pp. 157-172.

[3] E.J. Berger, C.M. Krousgrill and F. Sadeghi, "Stability of Sliding in a System Excited by a Rough Moving Surface," ASME, vol. 119, pp. 672-680, October 1997.

[4] B. Bhushan, "Principle and Applications of Tribology," John Wiley \& Sons, Inc., New York, 1999, pp. 344-430.
[5] D. Godfrey, "Vibration reduces metal to metal contact and causes an apparent reduction in friction," ASME Trans., vol. 10, pp. 183$192,1967$.

[6] T. Skare, and J. Stahl, "Static and dynamic friction processes under the influence of external vibrations," Wear, vol. 154, pp. 177-192, 1992.

[7] A. Lehtovaara, "Influence of vibration on the kinetic friction between plastics and ice," Wear, vol. 115, pp. 131-138, 1987.

[8] D.M. Tolstoi, G.A. Borisova, and S.R. Grigorova, "Friction reduction by perpendicular oscillations," Sov. Phys. Dokl., vol. 17, pp. 907-909, 1973.

[9] O. Wertheim, and I. Bucher, "On the influence of controlled vibration on friction," Research Supported by the ISARELI Academy for Science (Grant. No. 030072), 2000.

[10] W. Lenkiewicz, "The sliding process - effect of external vibrations," Wear, vol. 13, pp. 99-108, 1969.

[11] V. Aronov, A.F. D'souza, S. Kalpakjian, and I. Shareef, "Interactions among friction, wear, and system stiffness-part 1: effect of normal load and system stiffness," ASME J. Tribol., vol. 106, pp. 54-58, 1984.

[12] V. Aronov, A.F. D'souza, S. Kalpakjian, and I. Shareef, "Interactions among friction, wear, and system stiffness-Part 2: vibrations induced by dry friction," ASME J. Tribol., vol. 106, pp. 59-64, 1984.

[13] V. Aronov, A.F. D'souza, S. Kalpakjian, and I. Shareef, "Interactions among friction, wear, and system stiffness-part 3: wear model," ASME J. Tribol., vol. 106, pp. 65-69, 1984.

[14] D.H. Hess, and A. Soom, "Normal vibrations and friction under harmonic loads: part i -hertzian contacts," J. Tribol, vol. 113, pp. 80-86, 1991.

[15] M.D. Bryant, and J.W. LIN, "Photoelastic visualization of contact phenomena between real tribological surfaces, with and without sliding," J. Wear, vol. 170, pp. 267-279, 1993.

[16] T. Skare, and J. Stahl, "Static and dynamic friction processes under the influence of external vibrations," Wear, vol. 154, pp. 177-192, 1992.

[17] M.A. Chowdhury, and M.M. Helali, "The effect of amplitude of vibration on the coefficient of friction", Tribol. Int., vol. 41, pp. 307-314, April 2008.

[18] M.A. Chowdhury, and M.M. Helali, "The frictional behavior of materials under vertical vibration", Industrial Lubrication and Tribology, Issue 3 (to be published), 2009.

[19] M.A. Chowdhury, and M.M. Helali, "The effect of direction of vibration on the coefficient of friction", Indian J. Tribol., Issue 1 (to be published), 2009.

[20] Y. Imada, and K. Nakajima, "Effect of humidity on the friction and wear properties of Sn," J. Tribol., vol.117, pp. 737-744, October 1995.

[21] K. Komvopoulos, and H. Li, "The effect of tribofilm formation and humidity on the friction and wear properties of ceramic materials," J. Tribol., vol. 114, pp. 131-140, 1992.

[22] Y. Imada, "Effect of humidity and oxide products on the friction and wear properties of mild steel," J. Jpn. Soc. Tribol., vol. 114, pp. 131-140, 1996.

[23] M. A. Chowdhury, and M. M. Helali, "The effect of frequency of vibration and humidity on the wear rate", Wear, vol. 262, pp. 198203, January 2007.

[24] M.A. Chowdhury, and M.M. Helali, "The effect of frequency of vibration and humidity on the coefficient of friction", Tribol. Int., vol. 39, pp. 958-962, September 2006.

[25] B. Bhushan, Tribology and Mechanics of Magnetic Storage Devices, $2^{\text {nd }}$ ed., Springer-Verleg, New York, 1996.

[26] E. Rabinowicz, Friction Wear Mater, $2^{\text {nd }}$ Ed., Wiley, New York, 1995.

(c) Chowdhury and Helali; Licensee Bentham Open.

This is an open access article licensed under the terms of the Creative Commons Attribution Non-Commercial License (http://creativecommons.org/licenses/by$\mathrm{nc} / 3.0 /$ ), which permits unrestricted, non-commercial use, distribution and reproduction in any medium, provided the work is properly cited. 